\title{
A Novel MRI and Clinical-Based Scoring System to Assess Post-Surgery Healing and to Predict Long-Term Healing in Cryptoglandular Anal Fistulas
}

\author{
Pankaj Garg $\mathbb{D}^{1,2}$, Vipul D Yagnik $\mathbb{D}^{3}$, Sushil Dawka $\mathbb{D}^{4}$, Baljit Kaur ${ }^{5}$, Geetha R Menon ${ }^{6}$ \\ 'Department of Colorectal Surgery, Indus Super Specialty Hospital, Mohali, Punjab, India; ${ }^{2}$ Department of Colorectal Surgery, Garg Fistula Research \\ Institute Surgery, Panchkula, Haryana, India; ${ }^{3}$ Department of Surgical Gastroenterology, Nishtha Surgical Hospital and Research Centre, Patan, \\ Gujarat, India; ${ }^{4}$ Department of Surgery, SSR Medical College, Belle Rive, Mauritius; ${ }^{5}$ Department of Radiology, SSRD MRI Imaging Centre, Chandigarh, \\ Haryana, India; ${ }^{6}$ National Institute of Medical Statistics, Indian Council of Medical Research, New Delhi, India
}

Correspondence: Pankaj Garg, Department of Colorectal Surgery, Indus Super Specialty Hospital, Mohali, Punjab, I40507, India, Fax +9 I 950 I0I I000, Email drgargpankaj@yahoo.com

Background: Anal fistulas cause great uncertainty and anxiety in patients and surgeons alike. This is largely because of the inability to accurately confirm postoperative fistula healing, especially long-term healing. There is no scoring system available that can objectively assess cryptoglandular anal fistulas for postoperative healing and can also accurately predict long-term healing.

Methods: Several parameters that could indicate anal fistula healing were assessed. Out of these, six parameters (four MRI-based and two clinical) were finalized, and a weighted score was given to each parameter. A novel scoring system (NSS) was developed. A minimum possible score (zero) indicated complete healing whereas the maximum weighted score $(n=20)$ indicated confirmed nonhealing. Scoring was done with postoperative MRI (at least 3 months post-surgery), then compared with the actual healing status, and subsequently correlated with the final long-term clinical outcome.

Results: The NSS was validated in 183 operated cryptoglandular fistula-in-ano patients over a 3-year period in whom 283 MRIs (preoperative plus postoperative) were performed. The postoperative follow-up was 12-48 months (median-30 months). The NSS was found to have a very high positive predictive value (98.2\%) and moderately high negative predictive value (83.7\%) for long-term fistula healing. Additionally, its sensitivity and specificity in predicting healing were $93.9 \%$ and $94.7 \%$, respectively.

Conclusion: Thus, this new scoring system is highly accurate and would be a useful tool for surgeons and radiologists managing anal fistulas. By objectivizing the assessment of postoperative healing, it can both ease and streamline management. Moreover, reliable prediction of recurrence-free long-term healing will greatly allay the apprehensions associated with this dreaded disease.

Keywords: anal fistula, MRI, postoperative, scoring system, internal opening, healing

\section{Introduction}

Anal fistulas, especially the complex types, are notorious and dreaded by patients as well as surgeons all across the globe. ${ }^{1-3}$ And this is not without reason. Apart from difficult anatomy, involvement of sphincters, lack of a gold-standard treatment, etc., an important reason is the inability to confidently and accurately assess fistula healing in the postoperative period. ${ }^{1,4-6}$ This problem is compounded by recurrence of the fistula months to years after it had apparently healed well. ${ }^{4,7}$ Understandably, this causes immense frustration and anxiety to the operated patients and the treating surgeons who are always fearful of "fistula coming back" even when the fistula appears clinically healed. ${ }^{9,10}$ There are no established standardized criteria to assess postoperative healing after surgery of cryptoglandular anal fistulas. ${ }^{4}$ So, there was a need to develop a scoring system which could help to objectively assess postoperative healing in fistulas. The main desired outcome of any fistula surgery is long-term healing. ${ }^{11}$ Therefore, any scoring system would be beneficial if, along 
with assessing postoperative healing, it also correlates accurately with long-term healing. Though scoring systems have been developed for assessing response to treatment in Crohn's anal fistula, there is no scoring system available for cryptoglandular anal fistulas. Therefore, a scoring system was developed based on MRI parameters and clinical assessment. The efficacy of the new scoring system to predict long-term healing was evaluated in this study.

\section{Methods}

\section{Development of the New Scoring System}

Review of Parameters Which Could Affect Healing

The first step was to identify clinical and MRI parameters that could characterize fistula healing process most accurately among those available in the clinical records of the patients and studied in the literature. The purpose was to exclude those parameters which were potential confounders and did not characterize the healing process.

All possible parameters that had been studied in the literature and could potentially affect or characterize fistula healing were listed. ${ }^{4,12-17}$ These were:

1) Diabetes, 2) hypertension, 3) body mass index (obesity), 4) smoking, 5) lifestyle (sedentary), 6) number of fistula tracts, 7) location of fistula (intersphincteric/transsphincteric/suprasphincteric), 8) fistula extension (infralevator/supralevator), 9) preoperative hyperintensity (on MRI T2-weighted images) (absent/mild/pronounced), 10) preoperative collections or associated abscess (cavities $>3 \mathrm{~mm}$ diameter), 11) rectal wall involvement (proctitis), 12) rectovaginal/ anovaginal tract, 13) inflammatory mass (absent/focal/diffuse), 14) preoperative hyperintensity of fistula tracts (on MRI post-contrast T1-weighted images), 15) dominant feature of primary tract and extensions (fibrous/granulation tissue/pus-filled), 16) fistula length, 17) presence of associated co-morbid conditions (Crohn's disease, tuberculosis and previous radiotherapy), 18) preoperative amount of pus discharge from external opening or anus, 19) healing of fistula tract in the intersphincteric space in postoperative period (on MRI T2-weighted and STIR images), 20) development of a new abscess in postoperative period, 21) flatus passage from external opening in postoperative period (even occasionally), 22) healing of external tracts in ischiorectal fossa in postoperative period (on MRI T2-weighted and STIR images), 23) healing of internal (primary) opening in postoperative period (on MRI T2-weighted and STIR images), 24) amount of pus discharge from external opening or anus in postoperative period.

We realized that the first 18 parameters indicated the presence or absence of comorbidities, preoperative fistula characteristics or complexity. However, our intent was to identify those parameters that could accurately track the healing process postoperatively at three months. All the parameters were independently assessed by all four experts (PG, VDY, $\mathrm{SD}, \mathrm{BK}$ ) as to whether they characterize fistula healing in the postoperative period. A consensus was reached among all the experts that the six parameters (no 19-24) were found to be the ones that characterised the healing process the most and were included in the scoring system (Table 1).

Table I Parameters Assessed After 3 Months of Surgery Which Indicate Fistula Healing

\begin{tabular}{|c|c|}
\hline S. No & Parameter \\
\hline \multicolumn{2}{|r|}{ MRI assessment-After 3 months of surgery } \\
\hline I & Healing of internal (primary) opening \\
\hline 2 & Healing of fistula tract in the intersphincteric space \\
\hline 3 & Healing of external tracts in ischiorectal fossa \\
\hline 4 & Non- development of a new abscess in intersphincteric space in the postoperative period \\
\hline \multicolumn{2}{|r|}{ Parameters that can be assessed only by clinical assessment after 3 months } \\
\hline 5 & No passage of flatus from any of the external openings \\
\hline 6 & No discharge (pus or serous) from any external opening or anus \\
\hline
\end{tabular}




\section{Finalizing the Parameters}

The six parameters, shortlisted above, which characterised the healing process, were given uniform scores as summarized below. The parameters were

1. Healing of the internal (primary) opening (on MRI) (healed $=0 /$ not healed $=1$ )

2. Healing of the fistula tract in the intersphincteric space (on MRI) (healed $=0 /$ not healed $=1$ )

3. Healing of the external tracts in ischiorectal fossa (on MRI) (healed $=0 /$ not healed $=1$ )

4. Development of new abscess in intersphincteric space in the postoperative period (on MRI) (absent $=0 /$ present $=1$ )

5. Passage of flatus from any of the external openings (clinical) (absent $=0 /$ present $=1$ )

6. Discharge (pus or serous) from any external opening or anus (clinical) (No discharge $=0$ /serous discharge $=1$ / purulent but $<50 \%$ of preoperative level $=2$ /purulent but $>50 \%$ of preoperative level $=3$ )

\section{Assigning Weight to Each Parameter}

We also realized that all the six parameters did not characterize or indicate fistula non-healing equally and hence needed to be given weights in order to develop accurate scores. To assign non-subjective weights to each of these parameters in terms of their predictive ability for healing (non-healing), we selected four researchers with extensive surgical and radiological experience in managing anal fistulas. ${ }^{18,19}$ They were independently asked to assign weights to each of these parameters on a scale of $0-5$ where lower weights meant lower ability to characterize and higher weights meant better ability to characterize healing/non healing. Once these researchers rated the parameters and provided the weights, we obtained the mean of these weights for each parameter rounded-off to the closest integer. Based on this method, the parameter nos. 1,2,4 and 5 were given a weight of 4 and parameter nos. 3 and 6 were given a weight of 1 (Table 2). We

Table 2 New Scoring System to Predict Long-Term Fistula Healing

\begin{tabular}{|c|c|c|c|c|c|}
\hline & Parameter & Scoring & Weight & $\begin{array}{l}\text { Maximum } \\
\text { Weighted } \\
\text { Score } \\
\text { Possible }\end{array}$ & $\begin{array}{l}\text { Minimum } \\
\text { Weighted Score } \\
\text { Possible }\end{array}$ \\
\hline & \multicolumn{4}{|l|}{ MRI assessment-After 3 months of surgery } & \\
\hline 1 & Healing of internal (primary) opening & Healed $=0$, Not healed $=1$ & 4 & 4 & 0 \\
\hline 2 & $\begin{array}{l}\text { Healing of fistula tract in the intersphincteric } \\
\text { space }\end{array}$ & Healed $=0$, Not healed $=1$ & 4 & 4 & \\
\hline 3 & Healing of external tracts in ischiorectal fossa & Healed $=0$, Not healed $=1$ & I & I & 0 \\
\hline \multirow[t]{2}{*}{4} & $\begin{array}{l}\text { Development of a new abscess in } \\
\text { intersphincteric space in the postoperative } \\
\text { period }\end{array}$ & $\mathrm{No}=0, \mathrm{Yes}=\mathrm{I}$ & 4 & 4 & 0 \\
\hline & \multicolumn{4}{|l|}{ Clinical assessment after 3 months } & \\
\hline 5 & $\begin{array}{l}\text { Flatus passage from any of the external } \\
\text { openings (even occasionally) }\end{array}$ & $\mathrm{No}=0, \mathrm{Yes}=\mathrm{I}$ & 4 & 4 & 0 \\
\hline 6 & Discharge from any external opening or anus & $\begin{array}{l}\text { No=0 } \\
\text { Serous=I } \\
\text { Purulent [less amount, }<50 \% \\
\text { of preoperative quantity) }=2 \\
\text { Purulent (high amount, }>50 \% \\
\text { of preoperative quantity) }=3\end{array}$ & I & 3 & 0 \\
\hline & & Total & & 20 & 0 \\
\hline
\end{tabular}

Notes: Total weighted score $<8$ - indicate healing, total weighted score $\geq 8$ indicate non-healing. 
then computed the weighted scores for each of these parameters by multiplying the scores of each parameter with the weights assigned by the researchers. Thus, a maximum weighted score of 20 (confirming fistula non-healing) and minimum weighted score of 0 (confirming fistula healing) was possible.

\section{Defining Cut-Off Score to Characterize Healing}

The next step was to decide on a cut-off score that characterized healing in the long run. For this, 20 patients (in whom long-term follow-up was available) were selected. The diagnostic indices (positive predictive value, negative predictive value, sensitivity and specificity) were computed for different cutoffs from 6 to 18. It was found that the best results were obtained when the cut-off was kept at a weighted score of 8 (positive predictive value $-100 \%$, negative predictive value$87.5 \%$, sensitivity- $92.3 \%$, specificity-100\%). Thus, a weighted score of $<8$ indicated that the fistula had healed at three months and would remain healed on a long-term basis. On the other hand, a weighted score of $\geq 8$ implied that the fistula had not healed at three months and would remain unhealed thereafter. These 20 patients were not included in the study.

\section{Study}

All consecutive patients operated for cryptoglandular anal fistula at a referral fistula center with a minimum follow-up of one year were screened retrospectively. Preoperative MRI was done in all the patients. The patients in whom postoperative MRI was done after surgery were selected and analyzed. Patients with associated comorbid conditions (uncontrolled diabetes, undetected tuberculosis, Crohn's disease or radiotherapy) were excluded. Long-term clinical healing was defined as the complete healing of all the fistula tracts (complete cessation of pus discharge from all the external openings and the anus) with a minimum follow-up of at least one year. Any pus discharge from even a single tract was taken as non-healing.

All the MRI scans were interpreted by two independent experts (BK, PG) (BK has 20 years and PG has 12 years of experience of MRI imaging in anal fistula patients ${ }^{18,19}$ ). All MRI scans were interpreted independently and then discussed to reach a consensus. Cases in which consensus could not be reached were excluded from the analysis. Since radiological healing takes at least $10-12$ weeks in most cases, ${ }^{19}$ it was decided that MRI assessment and scoring would be done at least three months after surgery.

All demographic and fistula-relevant parameters - horseshoe tract, associated abscess, recurrent fistula, multiple tracts, supralevator fistulas, suprasphincteric fistulas - were noted. The indication for post-operative MRI (whether for confirmation of fistula healing or to ascertain cause of non-healing), fistula healing status at the time of MRI and the long-term status of fistula healing were noted. The study was conducted in accordance with the Declaration of Helsinki and was approved by the Ethics Committee of the Indus International Hospital. Written informed consent was obtained from all the patients.

\section{MRI Acquisition Technique}

All MRI examinations were performed on a $1.5 \mathrm{~T}$ MR scanner (Achieva, Philips Medical Systems, Best, The Netherlands) using a 4-channels phased-array sense body coil. The long axis of the anal canal was identified by utilizing a midline sagittal localizing sequence. Subsequent transfers and coronal short inversion recovery sequences were planned with respect to the anal canal axis. Additional coronal T-2 W scans and axial T-1 W with respect to the anal canal axis were done in all patients. Sagittal T-1 weighted images were used in approximately $30 \%$ of patient at the discretion of the supervising radiologist when a presacral extension was suspected from the transfer short inversion time recovery images (STIR). No intravenous contrast material or endorectal/endoanal receiver coil was used. Established criteria for MRI diagnosis of anal fistula were used. The radiologist noted her opinion of primary opening, intersphincteric portion of fistula tract, all fistula extensions and tracts, fistula classification and any associated abscess.

\section{Parameters of Scoring System}

The scoring system had 6 parameters, 4 MRI-based and 2 clinical (Table 2). The scoring was done at the time of postoperative MRI scan (at least three months after surgery). The parameters were

MRI-based parameters 
1. Healing of internal (primary) opening: This was an important parameter and carried a high weightage. The active infected and patent internal opening appears hyperintense (white/bright) on T2-weighted and Short Tau-Inversion Recovery (STIR) sequences while it becomes hypointense (black) once it is healed. A patent internal opening implies a high chance of fistula non-healing. Therefore, non-healing of the internal opening was given a weight of 4.

2. Healing of fistula tract in the intersphincteric space: As with the internal opening, the active infected fistula tract in the intersphincteric space appears hyperintense (white/bright) on T2 and STIR and it becomes hypointense (black) once healed. This parameter was also given a weight of 4 .

3. Healing of external tracts in ischiorectal fossa: If an external tract was seen unhealed on MRI in the ischiorectal fossa lateral to (outside) the external sphincter, then a weight of 1 was given. This parameter was relatively less important because once the internal opening and fistula tract in the intersphincteric space had healed, the chances of long-term fistula healing were high.

4. Non-development of a new abscess in intersphincteric space: Development of a new abscess especially in the intersphincteric space while on treatment (after surgery) is quite ominous. It indicates progression of the disease process. It also raises the possibility of an undiagnosed associated disease like Crohn's disease, tuberculosis, etc. Therefore, a weight of 4 was given to this parameter as the chances of long-term non-healing of the fistula are quite high.

\section{Clinical Parameters}

1. No passage of flatus from any of the external openings: Though not a common symptom, passage of flatus from any of the external openings was a sensitive marker of the patent internal opening. Therefore, even occasional passage of flatus from the external opening after three months of surgery was given a weight of 4 .

2. No discharge (pus or serous) from any external opening or anus: Pus discharge is the cardinal symptom of fistula. But, at three months post-surgery, some serous discharge can occur from the healing (granulating) external tracts in the ischiorectal fossa. Therefore, a score of 1 was given to serous discharge, 2 was given to purulent discharge (less amount, $<50 \%$ of preoperative quantity) and 3 was given to purulent discharge (greater amount, $>50 \%$ of preoperative quantity). This parameter was given a weight of 1 .

\section{Results}

A total of 537 patients were operated for cryptoglandular anal fistula between June 2017 and June 2020. Preoperative MRI was done in all the patients. Postoperative MRI was done in 183 patients. These patients were selected and analyzed in detail. The patient and fistula parameters are tabulated in Table 3. The mean age was $40.1 \pm 11.4$ years and the M/F distribution was 157/26. There were $135(73.8 \%)$ recurrent fistulas, $74(40.4 \%)$ had an associated abscess, $158(86.3 \%)$ had multiple tracts, $72(39.3 \%)$ had a horseshoe tract, $41(22.4 \%)$ had a supralevator extension and $17(9.3 \%)$ were suprasphincteric fistulas. As per St James's University Hospital classification (SJUH), 94\% were complex fistulas while $6 \%$ were simple fistulas (Table 3).

A total of 283 postoperative MRI scans were performed in the selected 183 patients (Figure 1). The follow-up ranged from 12 to 48 months (median-30 months). The postoperative MRI at $\geq 3$ months post-surgery was available in 155/183 patients. Three patients had undetected tuberculosis in the peri-operative period and the diagnosis of tuberculosis was made 3 months after surgery. Therefore, these three patients were excluded. The new scoring was applied in 152 patients and the prediction of long-term healing by the NSS was then correlated with the actual final long-term clinical outcome.

Among the 152 patients who were analyzed, the NSS predicted healing in 109 patients (Table 4): 107/109 patients remained healed on long-term follow-up (Figures 2 and 3) while two patients had a recurrence (Figure 4). In 43/152 patients, the scoring system predicted non-healing of the fistula. In these patients, 36/43 patients had a recurrence and 7/ 43 healed on long-term follow-up (Figures 5 and 6). Thus, the NSS had a positive predictive value (PPV) of 98.2\% (107/ 109 ) in predicting long-term healing and a negative predictive value (NPV) of $83.7 \%$ (36/43). On the other hand, the 
Table 3 Patient Characteristics

\begin{tabular}{|c|c|c|}
\hline Parameter & \multicolumn{2}{|c|}{$N=183$} \\
\hline Follow-up in months (median) & \multicolumn{2}{|c|}{$12-48(30)$} \\
\hline Age $($ mean $\pm S D)$ & \multicolumn{2}{|c|}{$40.1 \pm 11.4$} \\
\hline M/F & \multicolumn{2}{|c|}{ 157/26 } \\
\hline Recurrent (\%) & \multicolumn{2}{|c|}{135 (73.8\%) } \\
\hline Abscess (\%) & \multicolumn{2}{|c|}{74 (40.4\%) } \\
\hline Multiple tracts (\%) & \multicolumn{2}{|c|}{ I58 (86.3\%) } \\
\hline Horseshoe (\%) & \multicolumn{2}{|c|}{$72(39.3 \%)$} \\
\hline Supralevator (\%) & \multicolumn{2}{|c|}{$41(22.4 \%)$} \\
\hline Suprasphincteric (\%) & \multicolumn{2}{|c|}{17 (9.3\%) } \\
\hline \multirow[t]{2}{*}{ Simple fistulas (lower grades) } & Parks- Grade I & $10(5.5 \%)$ \\
\hline & SJUH- Grade I \& II & II (6.0\%) \\
\hline \multirow[t]{2}{*}{ Complex fistulas (higher grades) } & Parks- Grade II-IV & I 73 (94.5\%) \\
\hline & SJUH- Grade III-V & 172 (94\%) \\
\hline
\end{tabular}

Abbreviation: SJUH, St James's University Hospital classification.

sensitivity and specificity of the new scoring system in predicting healing was $93.9 \%(107 / 114)$ and $94.7 \%(36 / 38)$, respectively.

In the subset of patients in whom the scoring system predicted healing and the fistula remained healed on long-term (true positive, $\mathrm{n}=107$ ), the mean weighted scores were $1.28 \pm 2.06$ (median-0) whereas in patients in whom the scoring system predicted healing but the fistula remained unhealed on long-term (false positive, $n=2$ ), the mean weighted scores were 0 (median-0) (Table 5). On the other hand, in the subset of patients in whom the scoring system predicted nonhealing and the fistula remained unhealed on long-term (true negative, $n=36$ ), the mean weighted scores were 10.4 \pm 1.6 (median-11) whereas in patients in whom the scoring system predicted non-healing but the fistula healed on long-term (false negative, $\mathrm{n}=7$ ), the mean weighted scores were 9.4 \pm 0.5 (median-9) (Table 5).

\section{Statistical Analysis}

The StatsDirect software for statistics was used (StatsDirect Ltd, Merseyside, UK). Fisher's exact test or chi-squared test were used to compare categorical variables. For normally distributed data, Student's $t$-test was used for the continuous variables in two samples. The cut-off point for significance was set at $\mathrm{p}<0.05$.

\section{Discussion}

Cryptoglandular fistulas are the most common type of anal fistula and they constitute $74.9 \%$ of all anal fistulas. ${ }^{20}$ This is the first scoring system developed to predict long-term healing in cryptoglandular anal fistulas and validated in a large cohort. Apart from a long-term follow-up, the strength of this study is that preoperative and postoperative MRI scans were done in all the patients $(\mathrm{n}=183)$. The scoring system was effective in assessing fistula healing 3 months after surgery and this assessment correlated accurately with long-term healing ( $>1$ year follow-up). This assumes immense importance because, till date, there is no method of predicting long-term healing in anal fistulas. The absence of a reliable method to predict long-term healing causes a lot of anxiety and frustration in patients as well as surgeons. Hence, the need for a reliable scoring system to predict long-term healing was greatly felt. ${ }^{21,22}$ All earlier scoring systems were developed in Crohn's fistulas and all of them assessed response of fistulas only to medical treatment. ${ }^{12-14}$ No scoring system till date has assessed healing of anal fistulas after surgery. Therefore, this novel scoring system, 


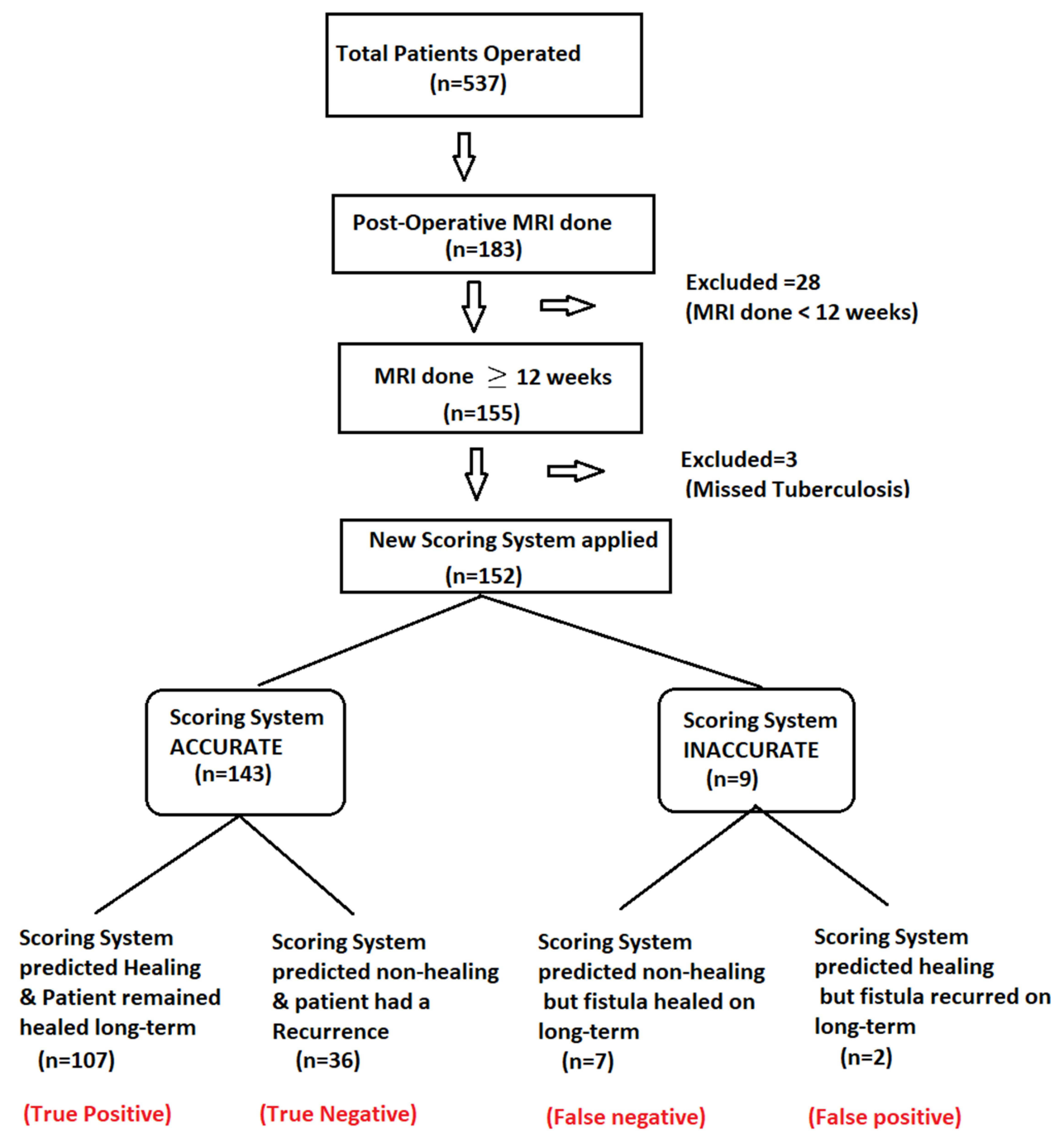

Figure I Flowchart of the study.

which assessed post-surgery healing in cryptoglandular fistulas, will be immensely useful for surgeons as well as radiologists managing this refractory disease.

The present study highlighted that the NSS has a reasonably high predictive value as well as specificity and sensitivity to confirm the status of fistula healing and, more importantly, its correlation with long-term healing. The PPV is very high (98.2\%) as 107/109 patients in whom the scoring system predicted healing remained healed on long-term follow-up. This

Table 4 Accuracy of Scoring System in Predicting Long-Term Healing

\begin{tabular}{|c|c|c|c|}
\hline & $\begin{array}{c}\text { Fistula Healed on Long- } \\
\text { Term }\end{array}$ & $\begin{array}{c}\text { Fistula NOT } \\
\text { Healed }\end{array}$ & \\
\hline Scoring system predicted healing (Weighted score <8) & $\begin{array}{c}107 \\
\text { (True Positive) }\end{array}$ & $\begin{array}{c}2 \\
\text { (False Positive) }\end{array}$ & $\begin{array}{l}\text { PPV- } 98.2 \% \\
(107 / 109)\end{array}$ \\
\hline \multirow[t]{2}{*}{ Scoring system predicted Non-healing (Weighted score $\geq 8$ ) } & $\begin{array}{c}7 \\
\text { (False Negative) }\end{array}$ & $\begin{array}{c}36 \\
\text { (True Negative) }\end{array}$ & $\begin{array}{c}\text { NPV- } 83.7 \% \\
\quad(36 / 43)\end{array}$ \\
\hline & $\begin{array}{c}\text { Sensitivity-93.9\% } \\
(107 / / 14)\end{array}$ & $\begin{array}{c}\text { Specificity- } 94.7 \% \\
(36 / 38)\end{array}$ & Total $=\mid 52$ \\
\hline
\end{tabular}

Abbreviations: PPV, positive predictive value; NPV, negative predictive value. 


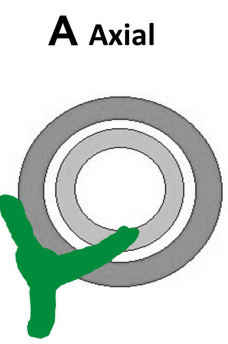

\section{B Coronal}
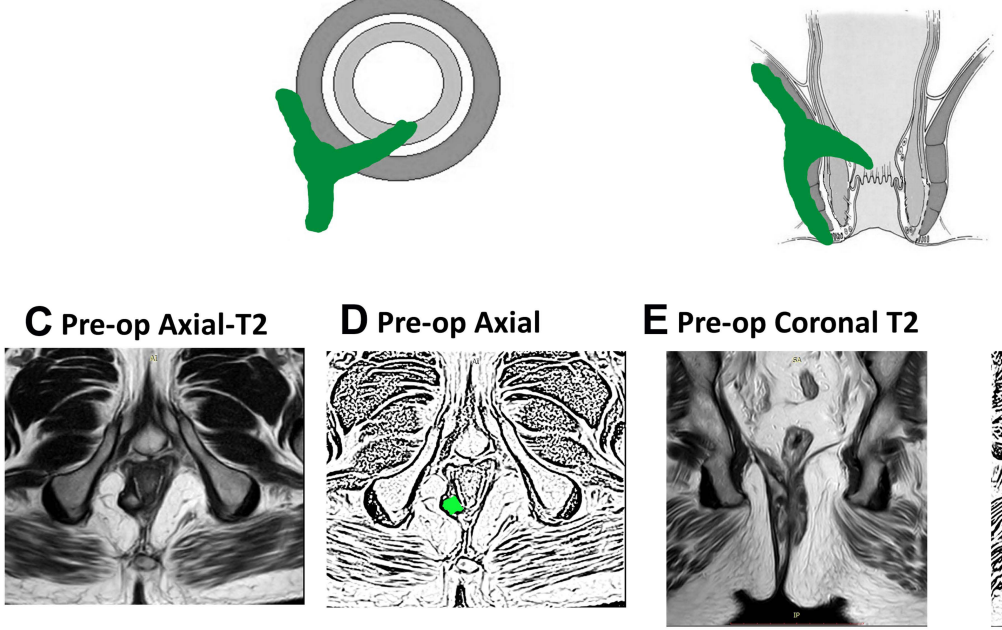

\section{F Pre-op Coronal}
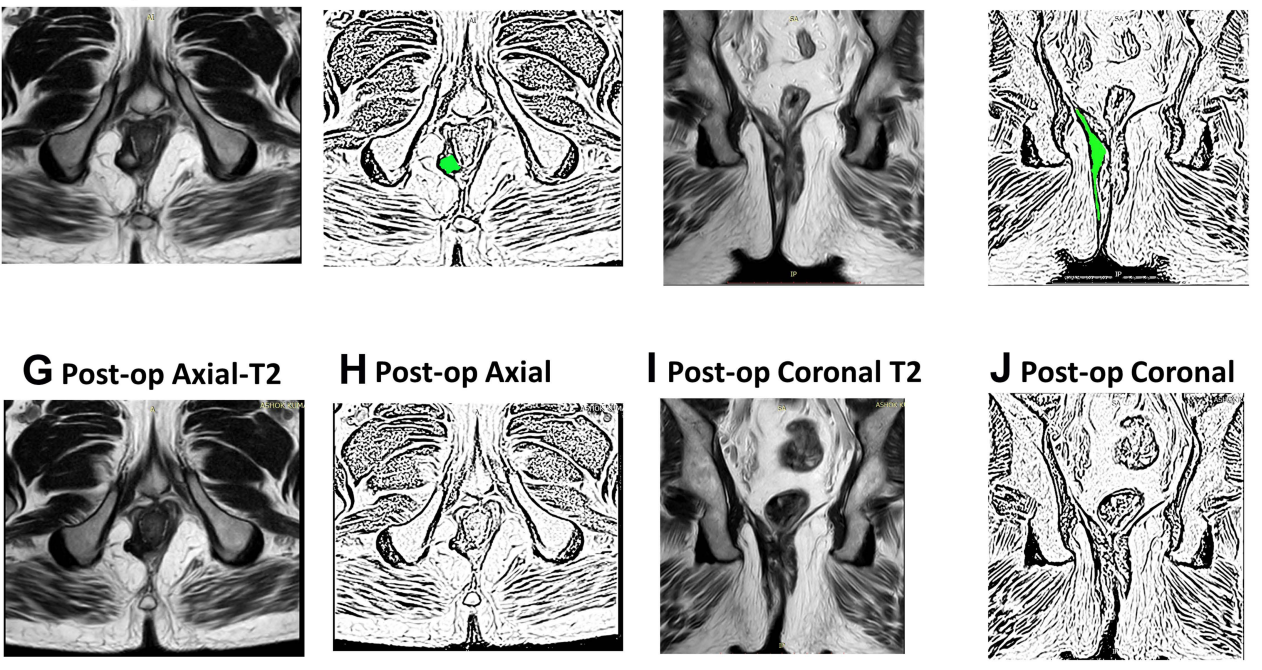

Figure 2 A 45-year-old male patient with a right-sided high transsphincteric fistula. MRI done 12 weeks after surgery showed complete healing. He had a weighted score of zero as per the new scoring system (NSS). The patient is asymptomatic at follow-up of 38 months. (A) Axial section (schematic diagram); (B) coronal section (schematic diagram); (C) pre-operative axial T2-weighted MRI showing high tract at 7 o'clock; (D) sketch of figure (C) highlighting high tract at 7 o'clock (green color); (E) preoperative coronal T2 weighted MRI showing high tract of right side; (F) sketch of figure-(E) highlighting high transsphincteric tract on right side (green color); (G) postoperative axial T2-weighted MRI showing healed fistula at 3 months; $(\mathbf{H})$ sketch of figure-(G); (I) post-operative coronal T2-weighted MRI showing healed fistula; (J) sketch of figure-(I).

is a remarkable finding because if the scoring system predicts healing (weighted scores $<8$ ) with such high accuracy in a particular patient, then the surgeon can convey to that patient with a fairly high confidence that the chances of fistula recurrence are minimal. In two patients, the fistula recurred even though the scoring system predicted complete healing and MRI showed complete resolution of disease (Figure 4). The speculated reason could be that the present fistula tract and the internal opening were perhaps so fine that there were no clinical symptoms and MRI could not detect it. Obviously, this is rare as the sensitivity of MRI is very high. Therefore, false positivity occurred in less than $1 \%$ of patients.

However, the NPV (negative predictive value) is comparatively less (83.7\%) as 7/43 patients in whom the scoring system predicted non-healing (weighted scores $\geq 8$ ) actually healed on longer follow-up. This is understandable because complete healing can be delayed ( $>3$ months) due to several reasons. First, in patients with extensive disease and/or wide tracts, healing can take much longer. Second, healing varies from person to person. Third, there can be undetected or missed tuberculosis (even after testing), Crohn's or other associated diseases which can interfere with healing. Therefore, it is not pertinent to label the patient as unhealed if the fistula has not healed within the cut-off period ( 3 months). It would be prudent to wait if the disease is showing signs of resolution and to send additional samples for testing if tuberculosis or Crohn's disease is suspected.

The cut-off period for analysis of postoperative MRI was set at 3 months. The reason for this was that before 3 months, it is difficult to differentiate between post-operative tissue inflammation, healing granulation tissue and active fistula tract. ${ }^{19,22}$ Therefore, a cut-off of 3 months was chosen, though it is known that healing granulating tissue can, at times, take longer than 3 months to convert into fibrous tissue. ${ }^{19,22}$ No doubt, extending the cut-off to 6 months would 

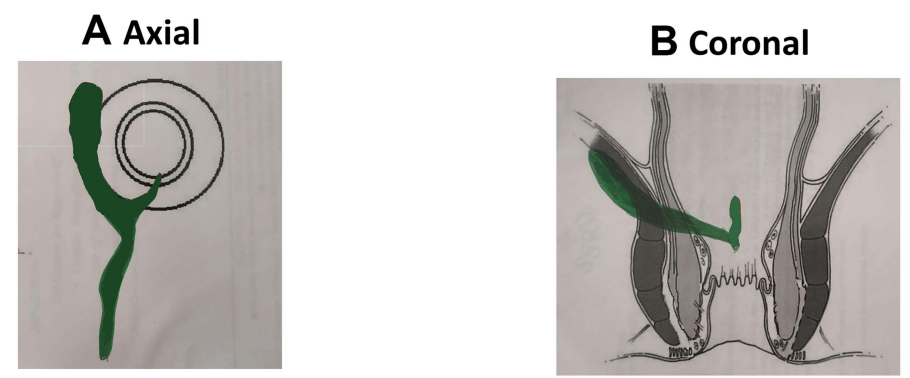

C Axial-T2: Pre-Op

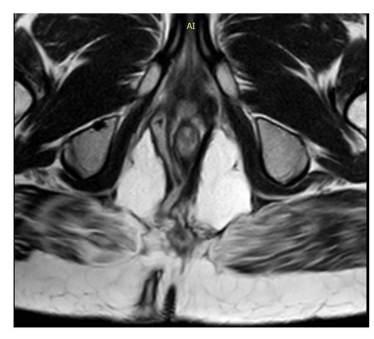

F Axial-T2: Post-Op (4 months)

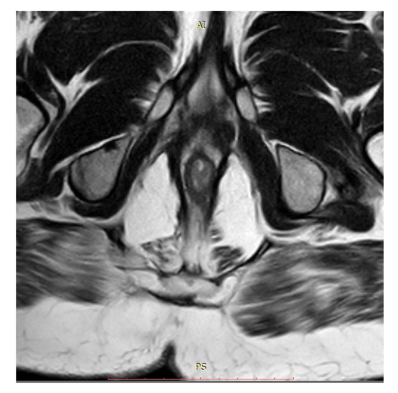

D Axial: Pre-Op

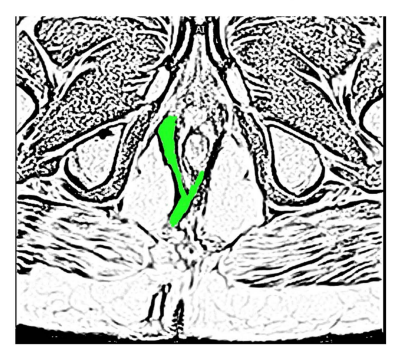

G Axial: Post-Op (4 months)

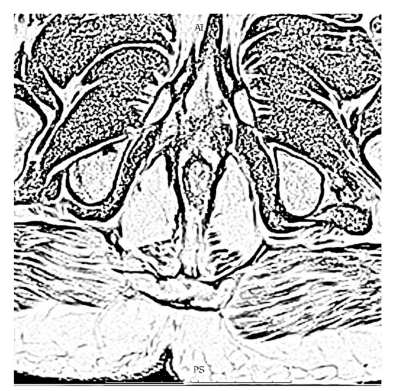

E Axial-STIR: Pre-Op

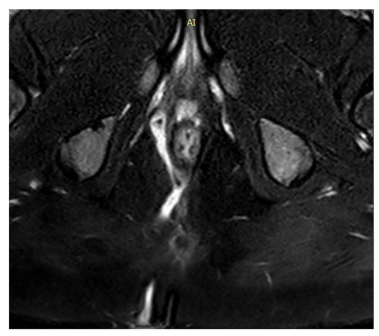

H Axial-STIR: Post-Op (4 months)

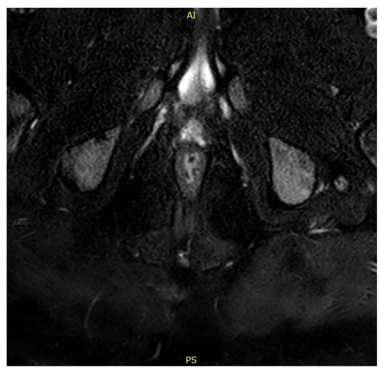

Figure 3 A 32-year-old male patient with a posterior high transsphincteric fistula. MRI done 16 weeks after surgery showed complete healing. He had a weighted score of zero as per the new scoring system (NSS). The patient is asymptomatic after a follow-up of 30 months. (A) Axial section (schematic diagram); (B) Coronal section (schematic diagram); (C) Pre-operative axial T2-weighted MRI showing high tract on right side; (D) Sketch of figure-(C) highlighting high tract on right side (green color); (E) Pre-operative axial STIR MRI; (F) Post-operative axial T2-weighted MRI showing healed fistula at 4 months; (G) Sketch of figure (F); (H) Post-operative axial STIR MRI showing healed fistula. STIR: Short-TI Inversion Recovery.

have made scoring more accurate, but it was felt that waiting for 6 months to confirm fistula healing would be practically difficult. Additionally, it would increase both patients' anxiety and expense (more follow-up visits). There were patients $(\mathrm{n}=7)$ in whom the fistula was not healed in the first postoperative MRI but the trend showed progressive healing. The "watchful expectancy" and follow-up for longer periods (4-12 months) led to complete resolution of the disease in these patients (Figures 5 and 6). Since there were only 7/152 (4.6\%) patients in whom delayed healing occurred, setting the cut-off at a minimum of 3 months seemed justified.

In the literature, scoring systems have been developed for perianal Crohn's disease to assess the response of fistulas to medical treatment. The first scoring system was developed in 2003 by Van Assche et $\mathrm{al}^{14}$ to check the effects of infliximab on perianal Crohn's disease in 18 patients. It was modified in 2017 by Samaan et al, who analyzed it in a cohort of 50 patients of Crohn's disease. Subsequently, a modified Van Assche scoring system was developed for fistulizing Crohn's disease. ${ }^{13}$ Another modification, MAGNIFI-CD scores, has also been proposed by Hindryckx et al in 


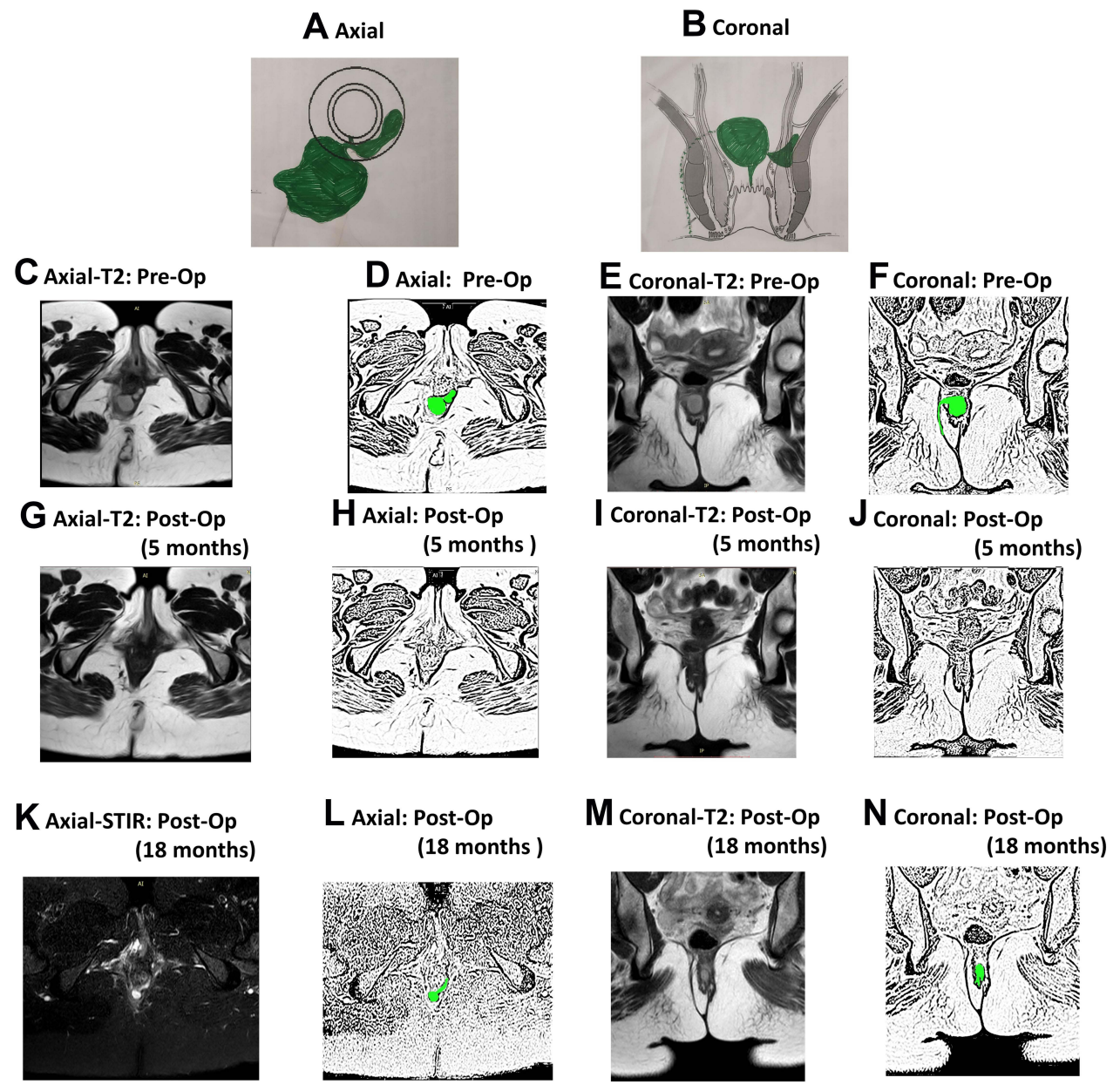

Figure 4 A 3 I-year-old female patient with a right-sided high transsphincteric recurrent fistulas and abscess. MRI done 20 weeks after surgery showed complete healing. She had a weighted score of three as per the new scoring system (NSS). The patient had a recurrence of fistula after 18 months. (A) Axial section (schematic diagram); (B) Coronal section (schematic diagram); (C) Pre-operative axial T2-weighted MRI showing right-sided abscess; (D) Sketch of figure-(C) highlighting right-sided abscess (green color); (E) Pre-operative coronal T-2 weighted MRI; (F) Sketch of figure-(E) highlighting abscess on right side (green color); (G) Post-operative axial T2-weighted MRI showing healed fistula at 5 months; (H) Sketch of figure-(G); (I) Post-operative coronal T2-weighted MRI showing healed fistula; (J) Sketch of figure-(I); (K) Post-operative axial T2-weighted MRI showing recurrence of fistula at the same site after 18 months; (L) Sketch of figure-(K); (M) Post-operative coronal T2-weighted MRI showing recurrence of fistula at 18 months; $(\mathbf{N})$ Sketch of figure $(\mathbf{M})$.

2019 to assess the response of Crohn's fistulas to stem cell treatment. ${ }^{12}$ All these scoring systems were limited to medical therapy of Crohn's disease and didn't include patients in whom surgery was performed.

However, recent studies have highlighted that these scoring systems proposed for Crohn's disease do not correlate accurately with postoperative healing. ${ }^{12,21}$ There could be multiple reasons for this. First, these scores use only MRIbased features and do not utilize any clinical parameters. ${ }^{12-14}$ This is perhaps an error as fistula healing is a clinical phenomenon and, for the scoring system to be comprehensive and accurate, clinical assessment parameters should be included. This could be the reason that the NSS proposed in the present study correlated quite well with healing because, unlike previous scoring systems, the NSS utilizes both MRI and clinical parameters. Secondly, the previous scoring systems included preoperative features of fistula complexity like supralevator extension, suprasphincteric tract, horseshoe tract, multiple tracts, etc. as their scoring parameters. ${ }^{12-14}$ The parameters that make a fistula complex preoperatively may decrease the chances of its healing, but these parameters are not necessarily the markers of fistula non-healing in the postoperative period. ${ }^{23-25}$ They are actually confounding parameters and do not accurately correlate with post-treatment healing. Hence, these parameters were not included in the NSS. The higher accuracy of the NSS as compared to previous scoring systems corroborates this point. Thus, any assessment of post-treatment healing should only take post-treatment healing parameters into consideration. 
A Axial
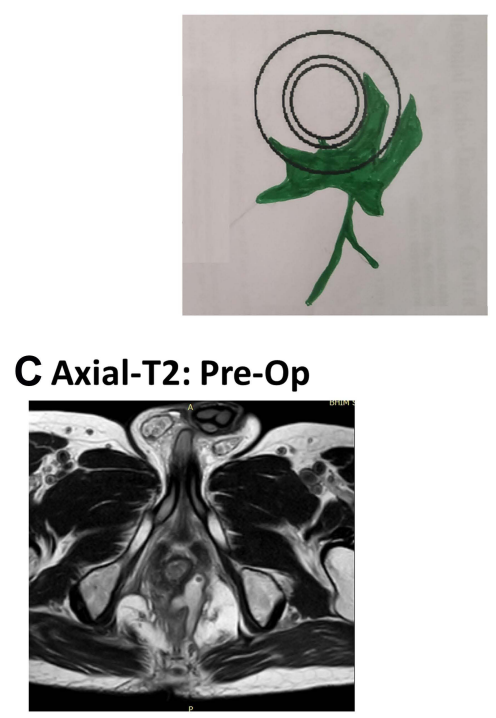

F Axial-T2: Post-Op (4 months)

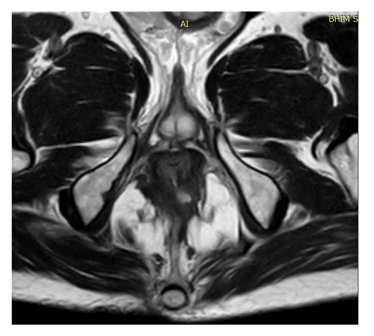

| Axial-T2: Post-Op (8 months)

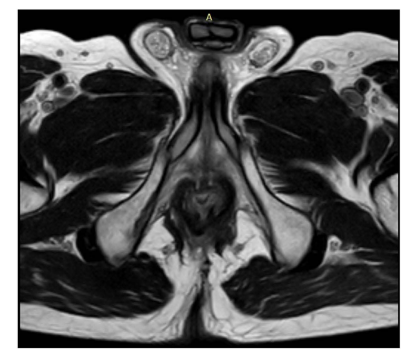

B Coronal
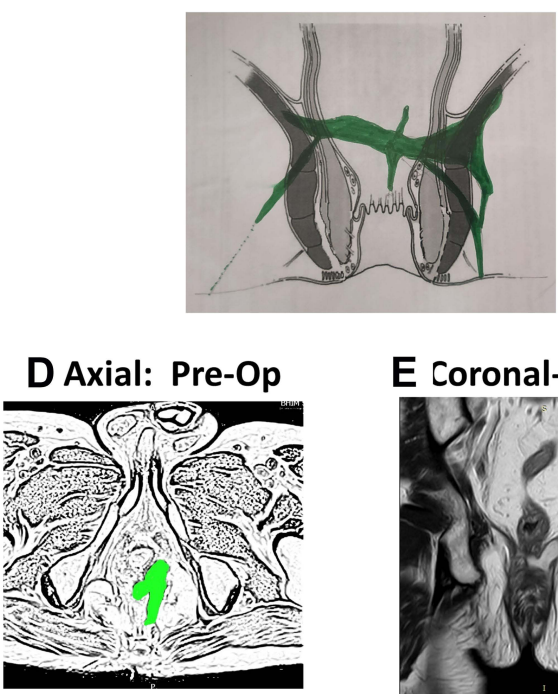

G Axial: Post-Op (4 months)

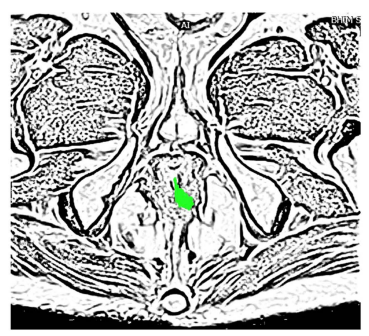

J Axial: Post-Op

(8 months)

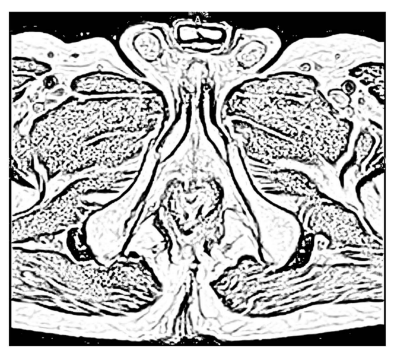

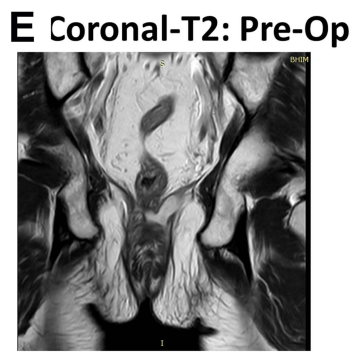

H Coronal-T2: Post-Op (4 months)

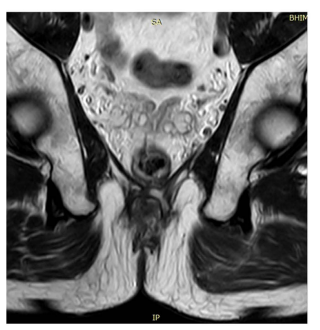

\section{K Coronal-T2: Post-Op} (8 months)

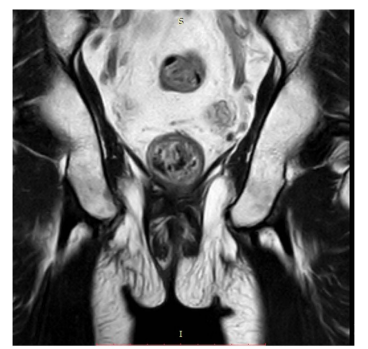

Figure 5 A 67-year-old male patient with a recurrent high transsphincteric horseshoe fistula. MRI done 4 months after surgery showed incomplete healing with a weighted score of 10 as per the new scoring system (NSS). The patient's fistula healed, confirmed by MRI done at 7 months. The patient is asymptomatic after a follow-up of 30 months. (A) Axial section (schematic diagram); (B) Coronal section (schematic diagram); (C) Pre-operative axial T2-weighted MRI; (D) Sketch of figure-(C) (fistula shown in green color); (E) Pre-operative coronal T-2 weighted MRI; (F) Post-operative axial T2-weighted MRI showing fistula not healed at 4 months; (G) Sketch of Figure 5 (fistula shown in green color); (H) Post-operative coronal T2-weighted MRI showing fistula not healed at 4 months after surgery; (I) Post-operative axial T2-weighted MRI showing fistula healed 8 months after surgery; (J) Sketch of figure-(I); (K) Post-operative coronal T2-weighted MRI showing fistula healed 8 months after surgery.

A majority of patients in the study had recurrent (74\%) and complex fistulas (94\%) (Table 3). This is understandable because the uncertainty of healing and the need to confirm healing by postoperative MRI is greater in such fistulas. A patient operated for a simple fistula for the first time would not be very interested in getting a postoperative MRI to check fistula healing and this is perhaps not indicated as well.

There are a few study limitations. First, this study was based on retrospective data analysis. Second, MRI is a prerequisite for the NSS; therefore, in regions or medical institutions where it is not easy to perform MRI after 

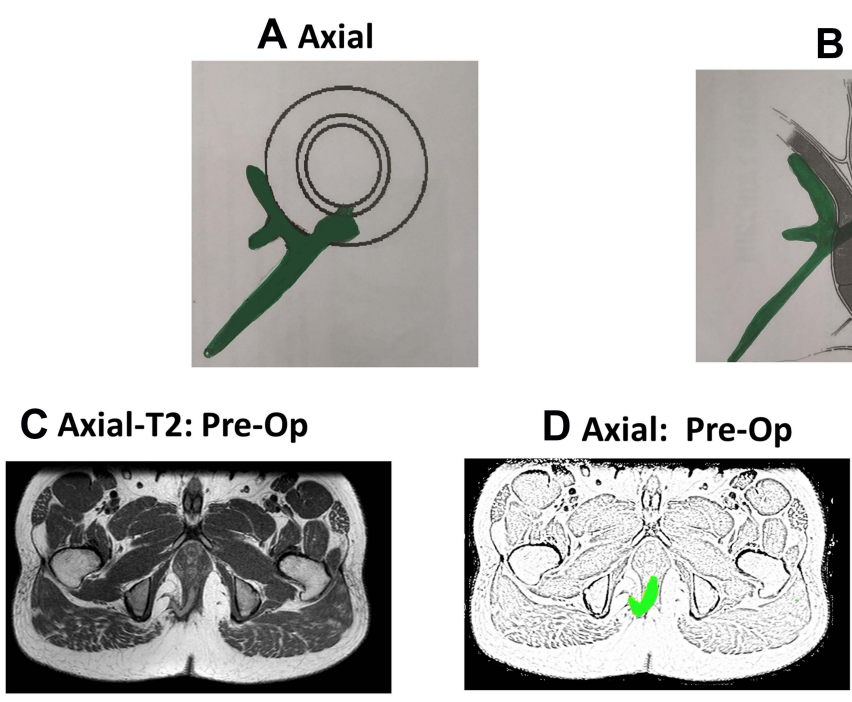

F Axial-T2: Post-Op (3 months)

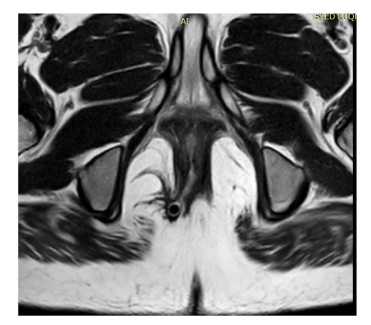

I Axial-T2: Post-Op (7 months)

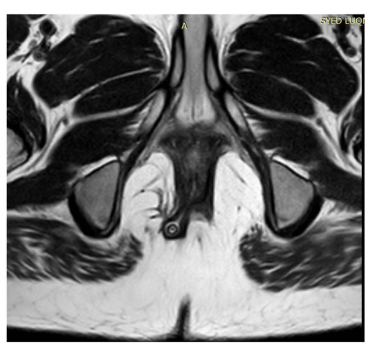

G Axial: Post-Op (3 months)

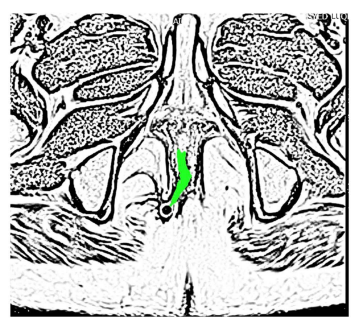

J Axial: Post-Op (7 months)

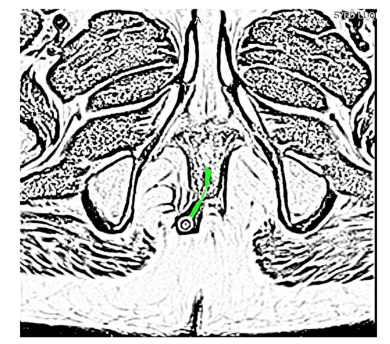

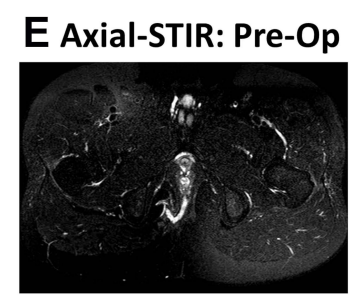

B Coronal

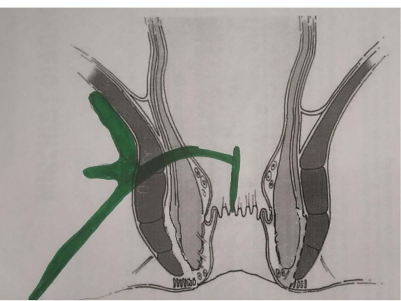

H Axial-STIR: Post-Op (3 months)

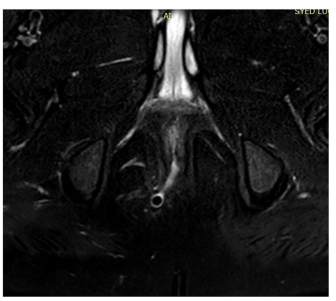

K Axial-STIR: Post-Op (7 months)

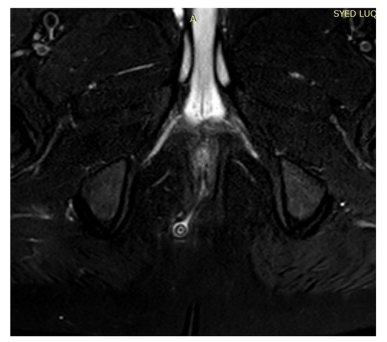

Figure 6 A 37-year-old male patient with a recurrent high transsphincteric fistula. MRI done 3 months after surgery showed incomplete healing with a weighted score of 9 as per the new scoring system (NSS). MRI done 7 months after surgery showed incomplete healing with a weighted score of 8 . The healing was slow but progressive as can be made out from sequential MRIs at 3 and 7 months. Therefore, the patient was kept under observation and the fistula healed completely 9 months after surgery. The patient is asymptomatic after a follow-up of 39 months. (A) Axial section (schematic diagram); (B) coronal section (schematic diagram); (C) pre-operative axial T2-weighted MRI; (D) sketch of figure-(C) (fistula shown in green color); (E) pre-operative axial STIR MRI; (F) post-operative axial T2-weighted MRI showing fistula not healed at 3 months; (G) sketch of figure-(F) (fistula shown in green color); $(\mathbf{H})$ post-operative axial STIR MRI showing fistula not healed at 3 months after surgery; (I) post-operative axial T2-weighted MRI showing fistula much smaller but still not healed 7 months after surgery; (J) sketch of figure-(I); (K) post-operative axial STIR MRI showing fistula not healed 7 months after surgery.

surgery, the NSS may not be applicable. Third, the selection of parameters that characterize healing was not performed by an objective method in a systematic review process. This was not possible because there are very few studies that have analyzed parameters on MRI which characterize long-term fistula healing ${ }^{4}$ and this is the first study on this topic (scoring system to predict long-term healing of cryptoglandular anal fistulas). Therefore, it was not possible to conduct a systematic review. An independent review of all possible parameters was performed by the four experts and a consensus was reached. The allotment of weight and deciding cut-off score to predict healing was also done in a non- 
Table 5 Weighted Scores in Each Group

\begin{tabular}{|l|l|l|l|l|}
\hline Scores & $\begin{array}{l}\text { True Positive (Scoring } \\
\text { System Predicted } \\
\text { Healing and Fistula } \\
\text { Healed on Long-Term) } \\
(\mathbf{n}=107)\end{array}$ & $\begin{array}{l}\text { False Positive (Scoring } \\
\text { System Predicted } \\
\text { Healing and Fistula } \\
\text { NOT Healed on Long- } \\
\text { Term) }(\mathbf{n}=2)\end{array}$ & $\begin{array}{l}\text { False Negative (Scoring } \\
\text { System Predicted } \\
\text { NON-Healing and } \\
\text { Fistula Healed on Long- } \\
\text { Term) }(\mathbf{n}=\mathbf{7})\end{array}$ & $\begin{array}{l}\text { True Negative (Scoring } \\
\text { System Predicted NON- } \\
\text { Healing and Fistula NOT } \\
\text { Healed on Long-Term) } \\
(\mathbf{n}=\mathbf{3 6})\end{array}$ \\
\hline Mean & $1.28 \pm 2.06$ & 0 & $9.4 \pm 0.5$ & $10.4 \pm 1.6$ \\
\hline Range & $0-8$ & 0 & $9-10$ & $9-17$ \\
\hline Median & 0 & 0 & 9 & 11 \\
\hline
\end{tabular}

subjective manner. The methodology might not have been optimal from the statistical point of view because of lack of published data; nonetheless, the high positive predictive value of the NSS as validated in a large cohort with a long-term follow-up corroborates the fairness of the conducted methodology.

To conclude, the new scoring system (NSS) is the first scoring system to be developed for cryptoglandular anal fistulas, to assess fistula healing after surgery and to predict fistula healing on a long-term basis. The scoring system was validated in a large cohort of 183 patients in whom preoperative and postoperative MRI as well as follow-up for longterm clinical outcome was done. The scoring system was found to have a very high positive predictive value (>98\%) and moderately high negative predictive value $(83.7 \%)$ for long-term fistula healing. Therefore, this scoring system may be extremely useful for surgeons and radiologists managing anal fistulas, especially complex fistulas. Further research at other centers is needed to corroborate the results of this study.

\section{Disclosure}

The authors report no conflicts of interest in this work.

\section{References}

1. Jayne DG, Scholefield J, Tolan D, et al. A multicenter randomized controlled trial comparing safety, efficacy, and cost-effectiveness of the surgisis anal fistula plug versus surgeon's preference for transsphincteric fistula-in-ano. Ann Surg. 2021;273(3):433-441. doi:10.1097/ SLA.0000000000003981

2. Pescatori M. Surgery for anal fistulae: state of the art. Int J Colorectal Dis. 2021;36(10):2071-2079. doi:10.1007/s00384-021-03917-7

3. Burke JP. Role of fecal diversion in complex Crohn's disease. Clin Colon Rectal Surg. 2019;32(4):273-279. doi:10.1055/s-0039-1683916

4. Garg P, Yagnik VD, Kaur B, Menon GR, Dawka S. Role of MRI to confirm healing in complex high cryptoglandular anal fistulas: long-term follow-up of 151 cases. Colorectal Dis. 2021;23(9):2447-2455. doi:10.1111/codi.15695

5. Wlodarczyk M, Wlodarczyk J, Sobolewska-Wlodarczyk A, Trzcinski R, Dziki L, Fichna J. Current concepts in the pathogenesis of cryptoglandular perianal fistula. $J$ Int Med Res. 2021;49(2):300060520986669. doi:10.1177/0300060520986669

6. Loder PB, Zahid A. Immediate treatment of anal fistula presenting with acute abscess: is it time to revisit? Dis Colon Rectum. 2021;64(4):371-372. doi:10.1097/DCR.0000000000001925

7. Mei Z, Li Y, Zhang Z, et al. Development of screening tools to predict the risk of recurrence and related complications following anal fistula surgery: protocol for a prospective cohort study. BMJ Open. 2020;10(3):e035134. doi:10.1136/bmjopen-2019-035134

8. Mei Z, Wang Q, Zhang Y, et al. Risk factors for recurrence after anal fistula surgery: a meta-analysis. Int J Surg. 2019;69:153-164. doi:10.1016/j. ijsu.2019.08.003

9. Adegbola SO, Dibley L, Sahnan K, et al. Development and initial psychometric validation of a patient-reported outcome measure for Crohn's perianal fistula: the Crohn's Anal Fistula Quality of Life (CAF-QoL) scale. Gut. 2020. doi:10.1136/gutjnl-2019-320553

10. Owen HA, Buchanan GN, Schizas A, Emmanuel A, Cohen R, Williams AB. Quality of life following fistulotomy - short term follow-up. Colorectal Dis. 2017;19(6):563-569. doi:10.1111/codi.13538

11. Halligan S, Tolan D, Amitai MM, et al. ESGAR consensus statement on the imaging of fistula-in-ano and other causes of anal sepsis. Eur Radiol. 2020;30(9):4734-4740. doi:10.1007/s00330-020-06826-5

12. Hindryckx P, Jairath V, Zou G, et al. Development and validation of a magnetic resonance index for assessing fistulas in patients with Crohn's disease. Gastroenterology. 2019;157(5):1233-1244 e1235. doi:10.1053/j.gastro.2019.07.027

13. Samaan MA, Puylaert CAJ, Levesque BG, et al. The development of a magnetic resonance imaging index for fistulising Crohn's disease. Aliment Pharmacol Ther. 2017;46(5):516-528. doi:10.1111/apt.14190

14. Van Assche G, Vanbeckevoort D, Bielen D, et al. Magnetic resonance imaging of the effects of infliximab on perianal fistulizing Crohn's disease. Am J Gastroenterol. 2003;98(2):332-339. doi:10.1111/j.1572-0241.2003.07241.x

15. Garg P, Kaur B. The new pathways of spread of anal fistula and the pivotal role of MRI in discovering them. Abdom Radiol (NY). 2021;46 (8):3810-3814. doi:10.1007/s00261-021-03029-4 
16. Garg P, Dawka S, Yagnik VD, Kaur B, Menon GR. Anal fistula at roof of ischiorectal fossa inside levator-ani muscle (RIFIL): a new highly complex anal fistula diagnosed on MRI. Abdom Radiol (NY). 2021;46(12):5550-5563. doi:10.1007/s00261-021-03261-y

17. Garg P, Kaur B, Yagnik VD, Dawka S, New Anatomical A. Pathway of spread of pus/sepsis in anal fistulas discovered on MRI and its clinical implications. Clin Exp Gastroenterol. 2021;14:397-404. doi:10.2147/CEG.S335703

18. Garg P, Kaur B, Goyal A, Yagnik VD, Dawka S, Menon GR. Lessons learned from an audit of 1250 anal fistula patients operated at a single center: a retrospective review. World J Gastrointest Surg. 2021;13(4):340-354. doi:10.4240/wjgs.v13.i4.340

19. Garg P, Kaur B, Yagnik VD, Dawka S, Menon GR. Guidelines on postoperative magnetic resonance imaging in patients operated for cryptoglandular anal fistula: experience from 2404 scans. World J Gastroenterol. 2021;27(33):5460-5473. doi:10.3748/wjg.v27.i33.5460

20. Garcia-Olmo D, Van Assche G, Tagarro I, et al. Prevalence of anal fistulas in Europe: systematic literature reviews and population-based database analysis. Adv Ther. 2019;36(12):3503-3518. doi:10.1007/s12325-019-01117-y

21. van Rijn KL, Lansdorp CA, Tielbeek JAW, et al. Evaluation of the modified Van Assche index for assessing response to anti-TNF therapy with MRI in perianal fistulizing Crohn's disease. Clin Imaging. 2020;59(2):179-187. doi:10.1016/j.clinimag.2019.10.007

22. Meima-van Praag EM, van Rijn KL, Monraats MA, Buskens CJ, Stoker J. Magnetic resonance imaging after ligation of the intersphincteric fistula tract for high perianal fistulas in Crohn's disease: a retrospective cohort study. Colorectal Dis. 2021;23(1):169-177. doi:10.1111/codi.15296

23. Garcia-Granero A, Sancho-Muriel J, Sanchez-Guillen L, et al. Simulation of supralevator abscesses and complex fistulas in cadavers: pelvic dissemination and drainage routes. Dis Colon Rectum. 2018;61(9):1102-1107. doi:10.1097/DCR.0000000000001136

24. Kedia S, Das P, Madhusudhan KS, et al. Differentiating Crohn's disease from intestinal tuberculosis. World J Gastroenterol. $2019 ; 25(4): 418-432$. doi:10.3748/wjg.v25.i4.418

25. Jayne DG, Scholefield J, Tolan D, et al. Anal fistula plug versus surgeon's preference for surgery for trans-sphincteric anal fistula: the FIAT RCT. Health Technol Assess. 2019;23(21):1-76. doi:10.3310/hta23210

Clinical and Experimental Gastroenterology is an international, peer-reviewed, open access, online journal publishing original research, reports, editorials, reviews and commentaries on all aspects of gastroenterology in the clinic and laboratory. This journal is indexed on American Chemical Society's Chemical Abstracts Service (CAS). The manuscript management system is completely online and includes a very quick and fair peer-review system, which is all easy to use. Visit http://www.dovepress.com/testimonials.php to read real quotes from published authors.

Submit your manuscript here: https://www.dovepress.com/clinical-and-experimental-gastroenterology-journal 